\title{
Hydrothermal synthesis and characterization of polycrystalline gadolinium aluminum perovskite $\left(\mathrm{GdAlO}_{3}, \mathbf{G A P}\right)$
}

\author{
Girish H. N. ${ }^{1,3 *}$, BASAVAlingu B. ${ }^{2}$, ShaO G.-Q. ${ }^{1}$, SAJAN C. P. ${ }^{1,3}$, S. K. VERMA ${ }^{3}$ \\ ${ }^{1}$ State Key Laboratory of Advance Technology for Material Synthesis and Processing, Wuhan University of Technology, \\ Loushi Road 122, Wuhan 430070, P. R. China \\ ${ }^{2}$ State Key Laboratory of Silicate Materials for Architectures, Wuhan University of Technology, No. 122, Luoshi Road, \\ Wuhan 430070, P. R. China \\ ${ }^{3}$ Department of Studies in Earth Science, University of Mysore, Mysore 570 006, India
}

\begin{abstract}
Gadolinium aluminum perovskite $\left(\mathrm{GdAlO}_{3}, \mathrm{GAP}\right)$ is a promising high temperature ceramic material, known for its wide applications in phosphors. Polycrystalline gadolinium aluminum perovskites were synthesized using a precursor of co-precipitate gel of $\mathrm{GdAlO}_{3}$ by employing hydrothermal supercritical fluid technique under pressure and temperature ranging from 150 to $200 \mathrm{MPa}$ and 600 to $700{ }^{\circ} \mathrm{C}$, respectively. The resulted products of GAP were studied using the characterization techniques, such as powder X-ray diffraction analysis (XRD), infrared spectroscopy (IR), scanning electron microscopy (SEM) and energy dispersive analysis of X-ray (EDX). The X-ray diffraction pattern matched well with the reported orthorhombic GAP pattern (JCPDS-46-0395).
\end{abstract}

Keywords: perovskite; hydrothermal process; co-precipitated gel; supercritical temperature

(C) Wroclaw University of Technology.

\section{Introduction}

The rare earth aluminates are of considerable interest because of their optical and magnetic properties and technological applications [1-3]. Rare earth aluminates serve as neutron absorbers, flux suppressors and high temperature container materials. These materials are also of considerable interest due to their magnetic and optical properties [4, 5]. Gadolinium aluminum perovskites are a kind of ceramics based on the $\mathrm{Ln}_{2} \mathrm{O}_{3}-\mathrm{Al}_{2} \mathrm{O}_{3}$ system ( $\mathrm{Ln}$ lanthanide element) and they are promising materials for optical, electronic and structural applications [6-8]. Perovskite aluminates doped with a lanthanide element offer advantages of longer lifetimes and higher polarized cross sections in comparison to most other oxide matrices. They are useful as hosts for solid-state lasers, luminescence systems and window materials for a variety of

*E-mail: girishhn25@gmail.com lamps. Transition metal perovskites are usually considered to be the most promising multiferroic materials. There exist hundreds of magnetic and ferroelectric perovskites. A good collection is presented in the tables compiled by Goodenough et al. [8]. Gadolinium aluminates are currently under development as candidate materials for the neutron absorption and control rod applications. Gadolinium compounds are widely used in the preparation of phosphors for color TV tubes. About $1 \%$ of gadolinium in iron, chromium and related alloys improves the workability and resistance to high temperature and oxidation. Since gadolinium is ferromagnetic, it can be used as a magnetic component in different sensing devices. Related ceramic perovskite materials are currently being incorporated into automobile catalytic converters; they are also promising substrates for the epitaxy of thin oxide films having potential use as buffer layers for the epitaxial growth of various perovskite-type films, such as high temperature superconductors, 
ferroelectrics, piezoelectric and colossal magnetoresistance oxides. Some perovskites also exhibit very large values of electric permittivity [2, 11-15].

Crystals of $\mathrm{GdAlO}_{3}$ perovskites have been prepared by several workers using different high temperature techniques, such as conventional and sol-gel techniques [14], melt method [15], flux method [16], microwave synthesis [17], organic synthesis with metal complexes [18] etc. However, these high temperature processes of preparation consume a lot of energy and lead to certain thermally induced strain in the resultant products, thus, affect their quality. The authors have explored the hydrothermal route for the preparation of $\mathrm{GdAlO}_{3}$. The first ever successful synthesis of orthorhombic $\mathrm{GdAlO}_{3}$ crystals employing hydrothermal technique under the influence of supercritical water/carbon dioxide is reported here for the first time.

\section{Experimental}

\subsection{Materials}

Gadolinium oxide (LOBA Chemie Co. Ltd, purity $99.9 \%$, extra pure), aluminum oxide (LOBA Chemie Co. Ltd., purity $99 \%$, neutral), nitric acid (LOBA Chemie Co. Ltd., purity $69 \%$, pure), ammonium solution (LOBA Chemie Co. Ltd.) and double distilled water have been used in the experiments. All the reagents were of analytical grade and used without further purification. Deionized water was used for post treatment processes.

\subsection{Preparation of gel}

Gadolinium aluminate $\left(\mathrm{GdAlO}_{3}, \mathrm{GAP}\right)$ polycrystalline ceramics were synthesized by a hydrothermal supercritical technique which was carried out using externally heated (Tuttle-Roy test tube type) pressure vessels. The used precursors were in a form of co-precipitated gels of gadolinium and aluminum. The co-precipitated gels were prepared by the method described by Hamilton et al. [19] for the preparation of silicate minerals. The targeted amount of $\mathrm{GdAlO}_{3}$ gels was prepared using stoichiometric amounts of analytic-grade $\mathrm{Gd}\left(\mathrm{NO}_{3}\right)_{3} \cdot 6 \mathrm{H}_{2} \mathrm{O}$ or $\mathrm{Gd}_{2} \mathrm{O}_{3}$ as $\mathrm{Gd}^{3+}$ raw materials and $\mathrm{Al}\left(\mathrm{NO}_{3}\right)_{3} \cdot 9 \mathrm{H}_{2} \mathrm{O}$ or $\mathrm{Al}^{3+}$ metal powder as $\mathrm{Al}^{3+}$ sources neutralizing the nitrate solution of gadolinium and aluminum oxide. The schematic flow chart of different steps involved in the preparation of co-precipitated gel was described by Basavalingu et al. [20]. The precipitate thus obtained was then scintillated above $600{ }^{\circ} \mathrm{C}$ until constant weights as well as the predetermined amount were achieved. If there was a weight deviation of more than $0.5 \%$, such gels were discarded.

\subsection{Hydrothermal synthesis of gadolin- ium aluminum perovskite}

The starting charge comprising the coprecipitated gel and water solvent were enclosed in platinum/gold capsules (4 mm diameter, $40 \mathrm{~mm}$ length, having a wall thickness of $0.1 \mathrm{~mm}$ ) and sealed by arc welding. The capsules were checked for any leakage after sealing and then placed in autoclaves. The experiments were carried out at different temperatures and pressures at different durations. The authors extended the process duration in order to check whether the crystal size improves with time. The crystalline $\mathrm{GdAlO}_{3}$ was obtained at a temperature of $700{ }^{\circ} \mathrm{C}$ and pressure $180 \mathrm{MPa}$ after 92 hour duration. The temperature and pressure were monitored constantly until they achieved the set values. The run was quenched with air blast followed by dipping the autoclave into a cold-water bath. The capsules were opened and the products were recovered carefully, washed, dried and subjected to XRD, FT-IR, SEM and EDAX studies for further characterization.

\section{Results and discussion}

\subsection{Characterization techniques}

$\mathrm{X}$-ray diffraction measurements of the obtained product were performed at room temperature on an X-ray diffractometer, RIGAKU, Miniflex II Series with a $\mathrm{CuK} \alpha$ radiation. The infrared spectra in the range of 4000 to $400 \mathrm{~cm}^{-1}$ were recorded using FT-IR spectrophotometer, Jasco 460 PLUS, Japan. Energy dispersive X-ray analyses (EDAX) were used for quantitative analysis and scanning electron microscope (SEM) model JEOL JSM-6380LA was 
used for studying the morphology and microstructure of the ceramic samples.

\subsection{X-ray diffraction}

The X-ray diffraction studies of the precursor, i.e. the co-precipitated gel (after scintillation in air above $600{ }^{\circ} \mathrm{C}$ ) used as the starting material confirmed that it was amorphous. The experimental run products were subjected to XRD studies, which confirmed that the obtained product is crystalline and belongs to orthorhombic $\mathrm{GdAlO}_{3}$ phase (Fig. 1). The XRD patterns match well with that reported for $\mathrm{GdAlO}_{3}$ phase of $\mathrm{PDF}=46-0395$. The refinement of cell parameters was done using CHECKCELL and the obtained cell parameters are given in Table 1 . The peaks in the region $23.8,33.1,42.0,48.9,53.8$ and 55.0 correspond to (002), (200), (202), (004), (114) and (312) planes, respectively. From the XRD pattern of the $\mathrm{GdAlO}_{3}$, it is clear that the synthesised compound possesses highly crystallized phase without any impurity.

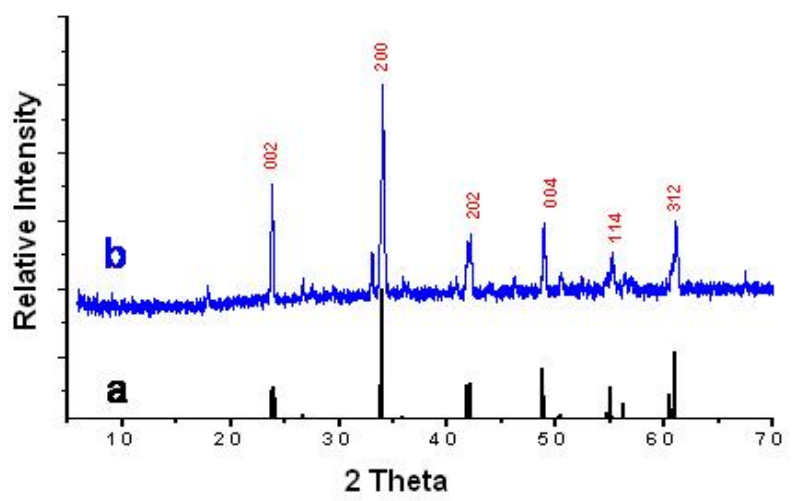

Fig. 1. XRD pattern of (a) JCPDS $=46-0395$, (b) synthesized $\mathrm{GdAlO}_{3}$.

\subsection{Infrared spectra}

The results of the X-ray diffraction analysis are consistent with the crystallization process observed by the IR measurements. IR analysis of synthesized samples is important for the control of both the reaction process and properties of obtained materials. Fig. 2 shows the FT-IR spectrum of $\mathrm{GdAlO}_{3}$. The sample of $\mathrm{GdAlO}_{3}$ exhibits the characteristic spectral pattern consisting of

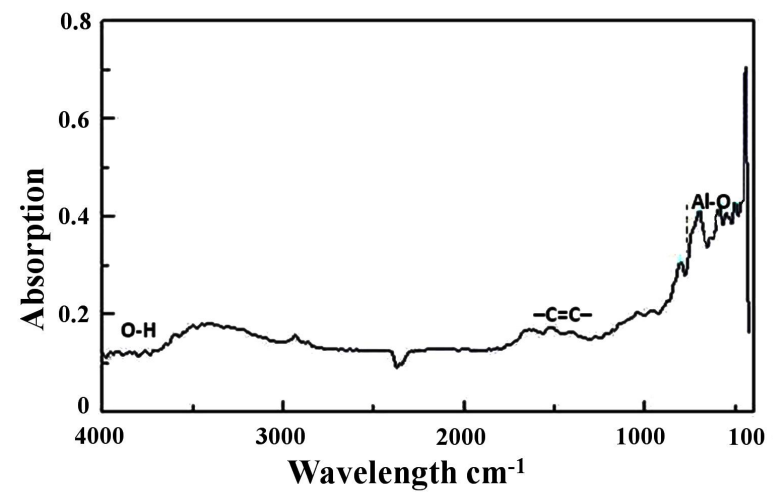

Fig. 2. FT-IR spectra of $\mathrm{GdAlO}_{3}$.

well-defined groups of sharp peaks in the range of 300 to $900 \mathrm{~cm}^{-1}$, which is in agreement with the reported data [21]. The band observed in the low-frequency region of the spectrum, corresponds to the lattice vibration mode and may be attributed to gadolinium oxygen $(\mathrm{Gd}-\mathrm{O})$ vibration at $520 \mathrm{~cm}^{-1}$. The IR spectra of $\mathrm{GdAlO}_{3}$ show peaks at frequencies of 660 and $465 \mathrm{~cm}^{-1}$ which are typical of the Al-O stretching frequencies characteristic vibrations in the perovskite structure compounds [22-24]. The strong and broad absorption band in the region from $3000 \mathrm{~cm}^{-1}$ to $3800 \mathrm{~cm}^{-1}$ corresponds to the $\mathrm{OH}$ mode which is due to the distilled water used in the post treatment process; on the other hand $-\mathrm{C}=\mathrm{C}-$ bond in the synthesized compound is represented by the peak at $1.570 \mathrm{~cm}^{-1}$ which is due to the absorption of atmospheric carbon.

\subsection{SEM and EDAX analysis}

The morphology and the particle size of obtained crystals were analyzed using SEM. The SEM images of a single phase $\mathrm{GdAlO}_{3}$ sample, obtained using the prepared co-precipitated gel of $\mathrm{GdAlO}_{3}$ as a precursor, are given in Fig. 3. The SEM images of the synthesized polycrystalline $\mathrm{GdAlO}_{3}$ show that all the crystals have a cubical shape and the size of 1.5 to $2.5 \mu \mathrm{m}$, and are highly crystalline and agglomerated.

The morphological study supported by the compositional analysis confirms again that the obtained crystals are orthorhombic and posses 
Table 1. Refined cell parameters of synthesized $\mathrm{GdAlO}_{3}$ compared with reported data.

\begin{tabular}{ccccc}
\hline Compound & a axis $(\AA)$ & b axis $(\AA)$ & c axis $(\AA)$ & Cell volume $\left(\AA^{3}\right)$ \\
\hline \hline $\mathrm{GdAlO}_{3}(\mathrm{PDF}=46-0395)$ & 5.251 & 5.301 & 7.445 & 207.27 \\
${\text { Synthesized } \mathrm{GdAlO}_{3}}$ & 5.244 & 5.301 & 7.444 & 207.00 \\
\hline
\end{tabular}

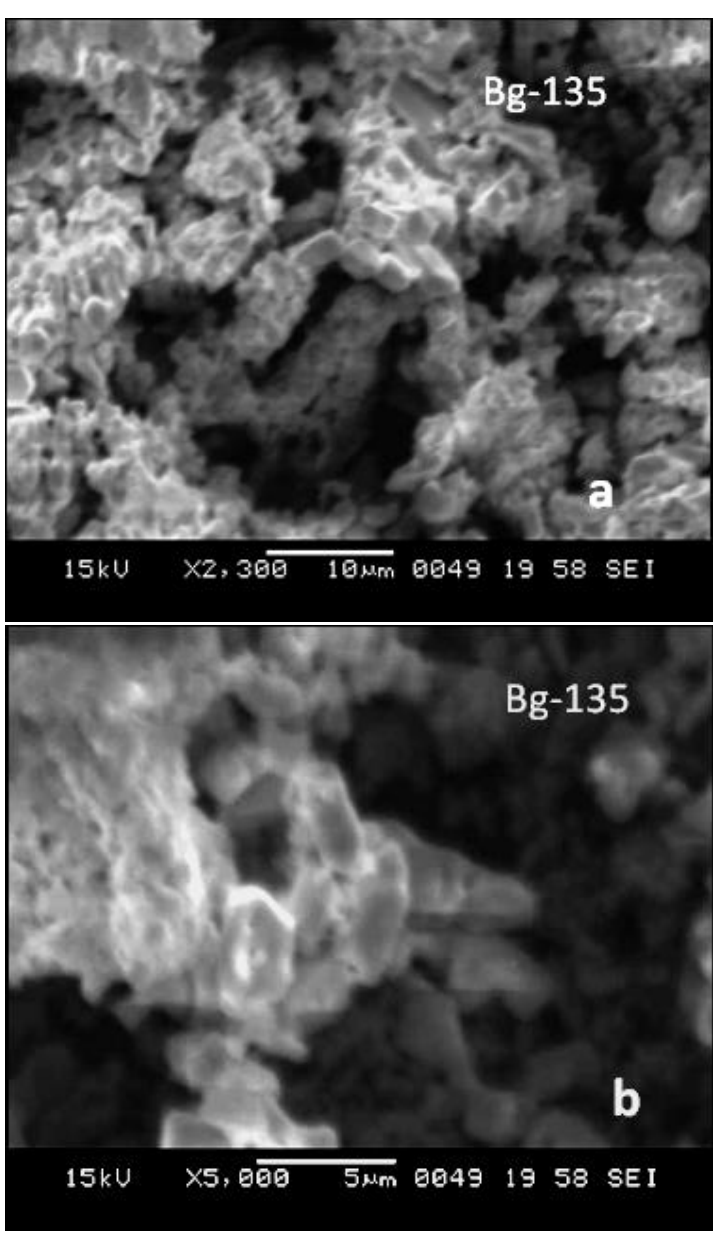

Fig. 3. SEM images of $\mathrm{GdAlO}_{3}$.

Table 2. Percentage composition of $\mathrm{GdAlO}_{3}$.

\begin{tabular}{ccccc}
\hline Run product & $\mathrm{O}$ at. $\%$ & $\mathrm{Al}$ at. $\%$ & $\mathrm{Gd}$ at. $\%$ & Total at. $\%$ \\
\hline $\mathrm{GdAlO}_{3}$ & 21.17 & 11.56 & 67.27 & 100 \\
\hline
\end{tabular}

nominal phase stoichiometry. The EDAX (energy dispersive analysis of X-rays) spectrum of a selected area of the $\mathrm{GdAlO}_{3}$ crystal is shown in Fig. 4. The atomic percentages of $\mathrm{Gd}, \mathrm{Al}$ and $\mathrm{O}$ were determined and are given in Table 2. The

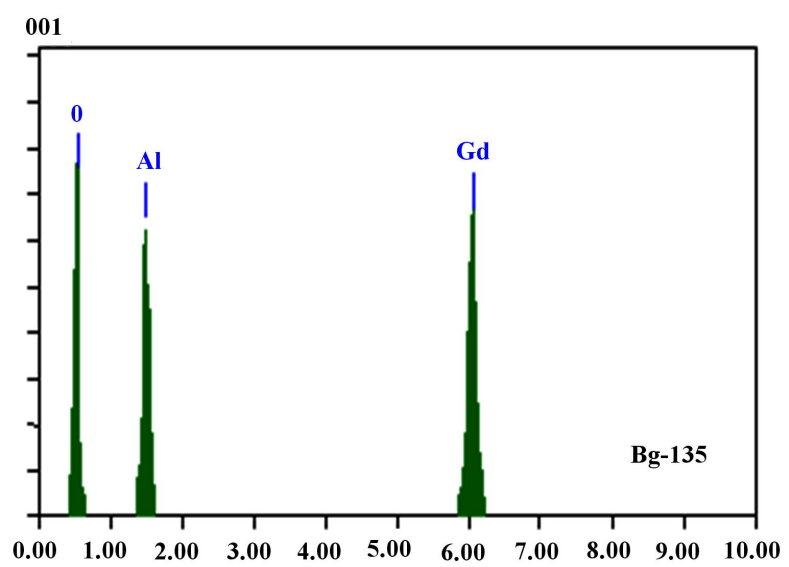

Fig. 4. EDAX of $\mathrm{GdAlO}_{3}$ crystal.

characteristic X-ray radiation of the elements stimulated by electron impact was detected up to a depth of several thousands micrometers.

\section{Conclusions}

The synthesis of $\mathrm{GdAlO}_{3}$ crystals under hydrothermal condition is sensitive to the nature of the used starting materials and the synthesis temperature. A single phase $\mathrm{GdAlO}_{3}$ has been difficult to synthesize so far due to the requirement of controlled stoichiometric composition. In this paper, we have clearly demonstrated the synthesis of $\mathrm{GdAlO}_{3}$ crystals employing hydrothermal technique, under the influence of supercritical fluid, which is encouraging for further investigations on the synthesis of similar oxides with several transition metals and the rare earth elements as dopants for specialized applications, such as lasers and phosphors.

\section{References}

[1] Cashion J.D., Cooke A.H., Hawkes J.F.P., Leask M.J.M., Thorp T.L., J. Appl. Phys., 39 (1969), 1360.

[2] Cashion J.D., CoOKe A.H., LeAsk M.J.M., ThorP T.L., Wels M.H., J. Mater. Sci., 3 (1968) 402. 
[3] Sivardiere J., Quezel-Ambrunas S., Compt. Rend., Paris, 1971.

[4] AtTField J.P., J. Inorg. Mater., 3 (2001), 1147.

[5] Atwood D.A., Yearwood B.C., J. Organomet. Chem., 600 (2000), 186.

[6] Malinowski M., Piramidowicz R., Frukacz Z., Chadeyron G., Mahiou R., Joubert M.F., J. Opt. Mater., 12 (1999), 409.

[7] Chroma M., Pinkas J., Pakutinskiene I., Beganskiene A., Kareiva A., Ceram. Int., 31 (2005), 1123.

[8] Goodenough J.B., Longo J.M, LAndoltBornstein, Magnetic Properties of Non-Metallic Inorganic Compounds Based on Transition Elements, New Series, Springer, Berlin, 1970, p. 126.

[9] Yada M., OHYa M.M., Machida M., KiJima T., Chem. Commun., 18 (1998), 1941.

[10] Nieminen M., SajavaARa T., Rauhala E., Putkonen M., NiInisto L.J., J. Mater. Chem., 11 (2001), 2340.

[11] Tall P.D., Coupeau C., Rabier J., Scripta Mater., 49 (2003), 903.

[12] Noginov M.V., J. Lumin., 109 (2004), 39.

[13] Retuerto M., Alonso J.A., Martinez-Lope M.J., MEnendez N., TORnero J., GARCIAHernandez M., J. Mater. Chem., 16 (2006), 865.

[14] Cizauskaite S., Reichlova V., Enartaviciene G., Beganskiene A., Pinkas J., Kareiva A.J., Mater. Sci-Poland., 25 (2007), 755.
[15] Harada Y., UeKawa N., Kojima T., KaKegawa K., J. Eur. Ceram. Soc., 29 (2009), 2419.

[16] Tomaz Catunda., Jose P., Andreeta, Jarbas C., CAstro, Appl. Optics, 25 (1985), 2391.

[17] Panneer Selvam M., Rao K.J., J. Adv. Mater. Covina, 12 ( 2000), 1621.

[18] King T.T., Rowlett B.A., Ramirez R.A., Shirron P.J., CANAVAN E.R, DiPIRro M.J., PANEK J.S., Tuttle J.G., Shull R.D., Fry R.A., $A d v$. Cryog. Eng., 613 (2002), 1191.

[19] Hamilton L., Henderson C.M.B., Text Book on Silicate Synthesis, 1958.

[20] Basavalingu B., Girish H.N., B yrappa K., Soga KoHeI., Mater. Chem. Phys., 112 (2008), 723.

[21] Han K.R., Koo H.J., Lim C.S., J. Am. Ceram. Soc., 82 (1999), 1598.

[22] SCHRADE B. (Ed.), Infrared and Raman Spectroscopy. Methods and Applications, VCH, Weinheim, 1995.

[23] Naкамото K. (Ed.), Infrared and Raman Spectra of Inorganic and Coordination Compounds, Wiley, New York. 1986.

[24] Vaqueiro P., Lopez-Quitela M.A., J. Mater. Chem., 8 (1998) 161.
Received 2014-11-13

Accepted 2015-01-26 